\title{
The Institute of Chemical Biology and Fundamental Medicine of the Siberian Division of the Russian Academy of Sciences (until 2003 the Novosibirsk Institute of Bioorganic Chemistry)
}

In the spring of 1957 , a decree of the Council of Ministers of the USSR founded the Siberian Branch of the USSR Academy of Sciences. At the beginning, this branch included 10 institutes, which were involved in various natural sciences. During the planning of the Siberian Branch of the USSR Academy of Sciences, no provision was made for an institute specializing in physical-chemical problems in biology. This new branch of science remained a pariah, because the leader of the country, N.S. Hrushtschev, was under the influence of the charlatan ideas of T.D. Lysenko. That is why Michael Alexeevich Lavrentyev, the man charged with organizing the Siberian Branch, could only create the Institute of Cytology and Genetics (ICG), headed by Nikolai Petrovich Dubinin, who undoubtedly understood the value of chemical and physical methods in modern biology. Even this veiled attempt at organizing molecular biology research failed as Hrushtschev arrived at the Novosibirsk Academic Town in person and removed Nikolai Dubinin from the post of ICG Director. The institute was saved after Dmitry Konstantinovich Belyaev became the new director. He was a progressive geneticist working with furproducing animals, a commodity much more understandable to the top officials, rather than the Drosophila fruit-fly, the research of which led to most of the fundamental discoveries in genetics. The future of biology in this country worried many prominent scientists. Among them was Nikolai Nikolaievich Vorozhtsov, a well-known organic chemist, who was appointed to organize the Institute of Organic Chemistry (IOC) under the Siberian Branch. He recruited many of his

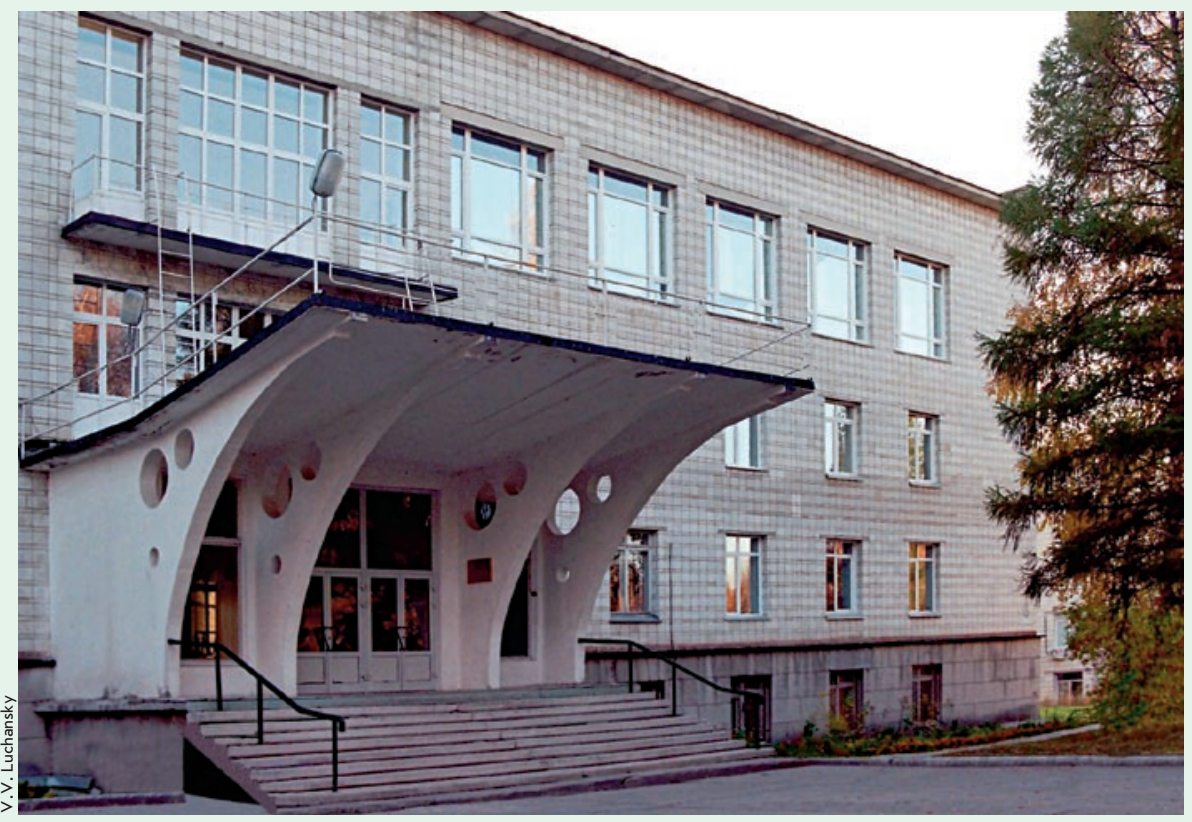

students, graduates of the Department of Intermediary Products and Dyes and also invited Dmitry Georgievich Knorre, who was very willing to use his knowledge of chemistry in studying life sciences. N.N. Vorozhtsov supported the young scientist in his wish and immediately agreed to create a Laboratory of Natural Polymers. The name was chosen carefully as the black shadow of Lysenko's influence was still not gone from biochemistry, and the use of "heretic" words such as proteins and especially nucleic acids as the name of a laboratory was unsafe. But the idea of creating a new line of scientific research in the Siberian Branch was firmly ingrained in the mind of N.N. Vorozhtsov, and in 1964 he reached an agreement with Michael Alexeevich Lavrentyev, who decided to construct a new building, intended especially for biochemical research. The building was completed in 1969 and it hosted the Biochemistry Department. Thus the Natural Polymer Lab received its true and unmasked name; it became the Nucleic Acid Chemistry Laboratory, and, together with the newly created Ultramicrobiochemistry Lab, it became the Biochemistry Department of the IOC of the Siberian Branch (now Siberian Branch of the Russian Academy of Sciences; SB RAS). It was Vorozhtsov's intention that the new department would combine with the laboratory headed by Rudolph Iosifovich Salganik, a leading biochemist who worked in the ICG SB RAS. This would allow the creation of a new institute. Alas, this intended path to create a new institute did not succeed. 
However, it did not prevent a productive and lasting cooperative relationship between D.G. Knorre and R.I. Salganik, which led to the creation of several biochemical manufacturing facilities, which were very much in need at that time, since the possibilities to buy chemicals and instrumentation with hard currency were very limited.

The issue of creating a new institute was raised again when Yuri Anatolievich Ovchinnikov attained the high post of vice-president of the USSR Academy of Sciences and, no less importantly, gained influence in government and party circles. For a long time, he advocated the creation of such an institute in Siberia. The recently appointed chairman of the Siberian Branch, Valentin Afanasievich Koptyug, also shared this view. As a result, the Decree of the CPSU Central Committee and the USSR Council of Ministers dated June 24, 1981, № 662 On the Further Development of Physical-Chemical Biology and Biotechnology and Their Use in Medicine, Agriculture and Industry had an article that stipulated the creation of the Novosibirsk Institute of Bioorganic Chemistry (NIBC). After several years of preliminary activities, the institute was officially approved in April 1984 and Dmitry Georgievich Knorre was appointed its first director.

The creation of the NIBC SB RAS played an important role in establishing physical-chemical biology in Siberia. A Molecular Biology Division was created in the Novosibirsk State University (NSU) at the Natural Sciences Department on the basis of the NIBC and the laboratory of R.I. Salganik. The division trained several hundred young specialists. This not only allowed to staff the two main biological institutes with young researchers, but also to create new institutions specializing in biochemistry. In particular, this fact played a major role in the choice of location for a large virology center. The Glavmicrobioprom (head organization for microbiological industries) chose a location adjacent to the Novosibirsk Academic Town, which eventually led to the formation of the scientific town of Koltsovo, a center of research and manufacturing of prophylactic drugs against most viral infections, including those deemed extremely dangerous. Now this center is called Vector, the state scientific virology and bacteri- ology center.

In 1996, D.G. Knorre turned 70 and left the post of director, and the newly elected director was D.G. Knorre's student, a corresponding member of RAS, Valentin Victorovich Vlasov (who became a full member of RAS in 2003). He decided that the most important applications of physical-chemical biology were medical, and so he strengthened this branch of the institute's research and created a division for novel medical technology in the institute. Thus, the institute received a new name in 2003; it became the Institute of Chemical $\mathrm{Bi}$ ology and Fundamental Medicine SB RAS (ICBFM).

Today, ICBFM is the main site for training specialized staff of all levels in the field of physical-chemical biology, starting with college graduates up to $\mathrm{PhD}$. and higher levels of academic research (Doctors of Science). Among the graduates of the Molecular Biology Division are Valentin Victorovich Vlasov, a full member of RAS, and corresponding members Olga Ivanovna Lavrik and Sergey Victorovich Netesov. A very important step in training staff of the highest qualification was the establishment within the institute of a Scientific Council empowered to award $\mathrm{PhD}$ degrees. More than $200 \mathrm{PhD}$. projects have been delivered and defended as of today. The institute continues to be actively involved in the training of students and post-graduates, specializing in the varied fields of chemistry and biology. The institute has post-graduate programs in 3 specialties and trains about 40 people every year.

The Chemical Biology and Fundamental Medicine Institute of SB RAS is well known for the level of its scientific research, and it has a high scientific potential, with a wonderful stock of modern research equipment. The institute is one of the acknowledged leaders among biological institutions in the Siberian Branch of RAS and in all of Russia. Every year, researchers from the institute publish more than 150 articles in leading Russian journals and in international peer-reviewed journals.

At present, the Institute includes 16 laboratories and research groups, and 2 divisions (the Molecular and Cell Biology Division and the Center of Novel Medical Technology). The institute employs about 200 scientists, including 3 full RAS members, 1 corresponding member, 18
Doctors of Science and $78 \mathrm{PhD}$. researchers. More than half of the scientific staff are young scientists under the age of 35. Several projects completed in the institute have received national prizes, such as the Lenin Prize, two State Prizes in the field of Science and Technology, the Russian Federation State Prize for Education, and a number of other Russian and international prizes, including awards for young scientists.

The main topics of research in the institute are the following:

- Studying the structure and function of biological molecules and supramolecular complexes; creating compounds which have specific effects on genetic structures; bioengineering and synthesis of biopolymers and synthetic biology.

- Biotechnology, including gene therapy, cellular technology for regenerative medicine, and nanobiotechnology.

- Clinical physiology, genetic basis of personalized medicine, molecular basis of immunity and oncogenesis

- The ecology of organisms and communities, communities of extremophilic microorganisms, viral and bacterial agents in mammal organisms.

Among the major scientific results obtained during the quarter century of the institute's existence are the following:

- The establishment of the fundamental basis for obtaining gene-directed bioactive compounds. The development of effective methods for the synthesis of nucleic acid fragments and their analogues and derivatives.

- Development of methods for the analysis of the structure and function of complex biopolymeric supramolecular ensembles.

- Creation of a technological basis for the diagnosis of genetic and infectious diseases and for the sequencing of the genomes of biological objects. The development of novel molecular tools and methods for the diagnosis of oncological, autoimmune, and infectious diseases.

Thus, having passed the stages of establishment and development, after 25 years of productive work, the institute has its own reputation, stands firmly on its feet and is actively conducting research, employing young specialists and the experience of the scientific schools created within the institute itself. 